\title{
Influences of Sources of Communication on Adoption of a Communication Technology
}

\author{
William D. Stuart ${ }^{1}$, Tracy Callaway Russo ${ }^{2}$, Howard E. Sypher ${ }^{2}$, Thelma E. \\ Simons $^{2}$, Lisa K. Hallberg ${ }^{2}$ \\ ${ }^{\prime}$ Longwood College \\ ${ }^{2}$ University of Kansas
}

\begin{abstract}
This study examined the influence of sources of information on end users' decision to adopt an innovation. The study used an on-line survey to collect data regarding respondents' perceptions of structured implementation activities and other sources of influence on their reported adoption of Microsoft Outlook at a large, Midwestern university. The research questions were based on Rogers' model of the diffusion of innovations, and the work of Fulk, Lewis and Seibold, and Weenig on the influences of information sources on adoption of innovations. Results showed that respondents who were exposed to information from informal channels and structured implementation activities (e.g., informational meetings conducted at the unit level) were significantly different from those who received no information through these channels. Perceptions of quantity or quality of information received through informal and official channels were not significantly correlated with adoption. The results indicate that the implementation of Outlook was not viewed as a major event in the life of the organization, and suggest that diffusion of technological innovations may be different from diffusion on non-technological innovations.
\end{abstract}

\section{RATIONALE}

The purpose of this study was to investigate the diffusion of an innovation within an organization. Specifically, the research focuses on the communication campaign developed to persuade administrators, faculty, staff, and students at a large Midwestern university to adopt a new communication technology. The technology investigated in this study is the groupware product, Microsoft Outlook. As groupware products offer their

The original version of this chapter was revised: The copyright line was incorrect. This has been corrected. The Erratum to this chapter is available at DOI: 10.1007/978-0-387-35404-0_19 
users a coherent variety of features, adoption in the current study was operationalized as the sum of subjects' reported frequency of use scores for all the features available. The investigation examined the influence of sources of information, source credibility, and valence of information on end-users' decision to adopt the new technology. These predictor variables were based on the literature regarding diffusion of innovations generally, and the diffusion of technology, specifically.

Diffusion theory is a popular means of investigating the proliferation of new ideas, policies, or products. Rogers (1995) defines diffusion as "the process by which an innovation is communicated through certain channels over time among the members of a social system" (p. 5). Rogers reports that 5000 studies using diffusion theory had been conducted by 1994 covering topics from the diffusion of hybrid corn in Iowa to videotape recorders, to water purification in Africa. Diffusion of innovations in organizations presents a specific context for the application and testing of diffusion theory, a context with unique challenges including the effect of interacting levels of responsibility and decision making, organizational roles, and organizational culture (Bunz, 1998; Speicher, 1997). The current study investigates the diffusion of a new communication technology within an intraorganzational context.

Researchers have demonstrated the importance of examining technology in organizations, because technology has the capacity to change organizations in a variety of ways. This can occur as technology changes the nature of jobs (Iacono \& Kling, 1986), or changes the form of organizations themselves (Allen \& Hauptman, 1990; Dawson, Drinkwater, Gunson, \& Atkins, 2000; Fulk \& DeSanctis, 1995). In addition to changes in the nature of organizations and jobs within organizations, technology may affect the social networks (Contractor \& Eisenberg, 1990; Feldman, 1987; Rice, 1994) and social processes (Poole \& DeSanctis, 1992) in the organization. It is important to understand new communication technologies, and how they diffuse, because they have and will continue to have profound affects on organizational life.

The current study pays particular attention to communication in the present diffusion initiative because communication is the cornerstone of diffusion (Marjahan \& Peterson, 1985). The individual level decision can be influenced by both formal communication and informal communication (Lewis \& Seibold, 1993, 1996; Weenig, 1999). Attention is paid to the valence of information gathered through social networks in the organization (Weenig, 1999). Valence refers to the attitude expressed (i.e., positive or negative) toward the technology. This is important because some scholars argue that technology is socially constructed (Fulk, 1993). That is, when individuals convey information and attitudes about a technology, their 
communication helps shape the attitudes and behaviors of other members of their social network, so valence of information would influence outcomes.

The literature concerning computer-mediated communication, the social construction of technology, and the diffusion of innovations suggests that when a technological innovation is presented to a potential adopter, information the individual receives from structured implementation activities can help provide general knowledge about the innovation and is the first step in the individual adoption decision process. The individual also is likely to receive information about the innovation from members of his or her social network, information that is likely to be influential in shaping the individual's attitudes and behaviors toward the technology. In order to investigate the relationships between these potential sources of influence and users' adoption of a communication technology, the following research questions are posed:

RQ1: What is the relationship between adoption of the innovation and receiving information through informal channels of communication and through the following structured implementation activities: official channels of communication (university and department officials, and/or publications), informal channels, initial informative presentation to the users, on-site introduction to installation, or installation consultant?

RQ2: What is the relationship between adoption of the innovation and the perceived credibility of sources of information?

RQ3: To what extent does adoption of the innovation vary if information received through informal channels is perceived as being positive or negative toward the innovation?

\section{METHOD}

The population for this study was individuals in faculty, administration, and support staff positions at a large Midwestern university who had Microsoft Outlook installed on their computers by staff members of Academic Computing Services at the university. The survey was distributed to approximately 1500 persons. This figure represents all the individuals who had the installation completed at the time the survey was distributed; that is, the survey was made available to $100 \%$ of the individuals who met the population parameters. A total of 509 responses were submitted. Out of these, 7 were completely blank, yielding a valid set of 502 completed surveys.

Individuals were invited to participate in the research process via an email from the Outlook Project Coordinator at the university. The e-mail 
message from the Coordinator described the nature and purpose of the study to potential respondents, and provided a link that respondents could click on to access the on-line survey.

The invitational messages/survey were distributed on Thursday, May 11, 2000. A reminder message was sent on Thursday, May 18, 2000, and data collection ended on Monday May 22, 2000. The message/reminder format is consistent with recommendations in the existing literature on on-line survey methods (Comely, 1996).

Although 11 days may seem a short period for data collection, previous research in this area suggests that an abbreviated period of data collection is not only possible, but is one of the advantages of on-line survey research. Comely (1996) lists an average response time of 4 days for e-mail surveys versus 11 days for postal surveys, and Smith (1997) states that "a large if not majority of survey responses are submitted within $24-48$ hours of exposure." These ideas were supported by the current study, in which 243 out of the 509 total responses $(48 \%)$ were received in the first 24 hours after exposure.

\section{RESULTS}

RQ1. Research Question One asks about the influence of utilization of sources of information on the decision to adopt. Sources of information included in the analyses were official sources (University or department officials or publications), informal channels, the initial informational presentation made to departments, the on-site presentation made to the departments at the time of installation, and information provided by the ACS consultant performing the installation on the individual's computer.

A series of bivariate correlations was performed to answer RQ1 (see Table 1). There were no significant correlations $(\mathrm{p}<.05)$ between utilization of sources of information and adoption of Outlook.

When examining individual components of Outlook, information received through informal channels was correlated with the use of the Folders (document sharing) function $(\mathrm{r}(351)=.16, \mathrm{p}=.03)$. Therefore, receiving more information about Outlook through informal channels was associated with more frequent use of the Folders function. No other significant correlations were found between sources of information and adoption of the individual components of Outlook. 
Table 1. Correlation of Utilization of Sources of Information with Adoption

\begin{tabular}{lccc}
\hline Independent variable & \multicolumn{1}{c}{} & $\mathrm{p}$ & Df \\
\hline Official channels & .03 & .50 & 495 \\
Informal channels & .05 & .38 & 349 \\
Informational & .06 & .30 & 357 \\
presentation & & & 372 \\
On-site introduction & .06 & .25 & 426 \\
Consultant & -.03 & .59 &
\end{tabular}

Approximately $25 \%$ of respondents indicated that they received no information from informal sources, the initial informational meeting, o the on-site introduction conducted at the time of installation. A majority of respondents received information from at least one of these sources. Follow up $t$ tests were conducted to determine if there were differences significant differences in adoption scores between individuals who received no information from these sources and those who utilized the sources. Results of the tests (see Table 2) indicated that for each of the three sources of information, respondents who were not exposed to the source of information were significantly less likely to adopt Outlook than those who were exposed.

Table 2. Differences in Adoption Based on Exposure to Sources of Information

\begin{tabular}{lllll}
\hline Source & $\begin{array}{l}\text { Not Exposed } \\
\mathrm{M}(\mathrm{SD})\end{array}$ & $\begin{array}{l}\text { Exposed } \\
\mathrm{M}(\mathrm{SD})\end{array}$ & $\mathrm{t}$ & $\mathrm{df}$ \\
\hline $\begin{array}{l}\text { Informal } \\
\text { Channels }\end{array}$ & $\begin{array}{l}19.33(7.50) \\
\mathrm{n}=151\end{array}$ & $\begin{array}{l}21.24(7.16) \\
\mathrm{n}=351\end{array}$ & $-2.70^{\mathrm{a}}$ & 500 \\
$\begin{array}{l}\text { Informational } \\
\text { Presentation }\end{array}$ & $\begin{array}{l}19.13(8.57) \\
\mathrm{n}=143\end{array}$ & $\begin{array}{l}21.27(6.66) \\
\mathrm{n}=359\end{array}$ & $-2.98^{\mathrm{a}}$ & 500 \\
On-site & $19.37(8.82)$ & $\begin{array}{l}21.11(6.67) \\
\mathrm{n}=374\end{array}$ & $-2.34^{\mathrm{b}}$ & 500 \\
Introduction & $\mathrm{n}=128$ & & & \\
& & & & \\
\hline
\end{tabular}

${ }^{\text {a }}$ Significant at $\mathrm{p}<.01$ level.

${ }^{\mathrm{b}}$ Significant at $\mathrm{p}<.05$ level.

The results of the $t$ tests are surprisingly different from the results of the correlations conducted to answer RQ1. These differing results are likely an effect of the different prompts used to assess the construct "utilization of sources of information." A comparison of the results of the two series of tests suggests that utilization of sources of information is important in terms 
of respondents' level of reported adoption, but perceptions of related constructs such as perceived amount of information or usefulness of the information seem less important.

RQ2. Research question two asks about the influence of perceived credibility of official and informal sources of information on the decision to adopt. Credibility of official sources of information was calculated by summing the scores for the items "official sources were well-informed" and "official sources were accurate."

Bivariate correlations were performed to answer RQ2. Neither credibility of official channels of information nor credibility of informal sources of information was found to be significantly correlated with the adoption of Outlook ( $\mathrm{p}<.05)$.

Perceived credibility of official sources of information was not significantly correlated with the adoption of Outlook $(\mathrm{r}(493)=.05, \mathrm{p}=.25)$. Perceived accuracy of information received through informal channels was not significantly correlated with adoption of Outlook $(\underline{r}(350)=-.06, p=$ .28).

Therefore, the credibility of sources of information did not appear to be associated with respondents' adoption of Outlook.

However, when considering the individual components of Outlook, the credibility of information received through informal channels was correlated with the use of the Tasks function $(r=-.11(350), p=.04)$. Therefore, respondents who perceived the information they received through informal channels as credible were less likely to utilize the Tasks function. No other significant correlations were found between sources of information and adoption of the individual components of Outlook.

RQ3. Research Question Three examined the influence of the valence of information received through informal channels on the decision to adopt. Valence refers to whether respondents perceived the information they received as being generally positive or negative toward Outlook. Respondents who indicated that they did not receive any information about Outlook through informal interactions were excluded from the analysis.

Results of a bivariate correlation revealed that no significant relationship existed between the valence of information received through informal channels and adoption ( $\mathrm{r}(364)=.08, \mathrm{p}=.14)$. Descriptive data suggest that respondents who did hear information about Outlook through informal sources generally heard positive things. However, the positive information respondents heard about Outlook apparently did not influence their adoption of the program. 


\section{DISCUSSION OF SURVEY DATA}

This investigation examined the relationship between end users' reported adoption of the technology and several potential influences on the decision to adopt: exposure to sources of information, perceived credibility of formal and informal channels of communication, and valence of information received through informal channels. Although respondents' perceptions of information and attitudes communicated about the technology were not found to be statistically related to adoption, exposure to information through informal channels and through certain official channels was correlated with adoption of Outlook. Communication of information and attitudes had been anticipated to have strong positive relationships with adoption of the technology in the current study, based on the literature on social construction of technology (Fulk, 1993). The results are surprising, in that Marjahan and Peterson (1985) describe communication as being central to the to the process of diffusion. Indeed, Rogers (1995) describes diffusion as a particular type of communication-communication about an innovation. In the current study, neither perceptions of formal nor informal sources of information, perceived source credibility, nor reported valence of information from informal sources were correlated with adoption.

However, there were significant differences between respondents who reported receiving no information from informal sources and two of the structured implementation activities and those who reported exposure to these sources. These results suggest that respondents' perceptions of the information they received from these sources did not matter as much as the fact that they exposed to the sources - and therefore the information - at all. That is, varying responses to sources of information such as perceived usefulness, helpfulness, or even amount of information were not important in this study; however, exposure to these sources was statistically significantly correlated with adoption of Outlook.

\subsection{Official Sources}

Lewis and Seibold (1993) state that organizations engage in a wide variety of structured implementation activities (formal sources of communication) in order to facilitate adoption of innovations.

The finding that exposure to structured implementation activities was associated with adoption contradicts Weenig (1999) and Rogers (1995), who indicate that formal channels are more useful for potential adopters to gather initial information about the innovation, rather than shaping attitudes and behaviors. In the current study, exposure to information from structured implementation activities was correlated with adoption. 
Although results in this study indicate that structured implementation activities are useful in facilitating adoption, this finding should be interpreted in the context of the wide variety of other influences on adoption beyond exposure to information in briefings and presentations. Lewis and Seibold (1993) note that in addition to structured implementation activities, which provide official sources of information about an innovation, there was a wide variety of other influences on the decision to adopt. Informal sources of information, user characteristics, innovation characteristics, and organizational structure and hierarchy can all influence the adoption or rejection of an innovation. Although results indicate that organizations should continue to invest time, money and effort in structured implementation activities in order to facilitate the diffusion of innovations, focusing solely on such efforts seems myopic. Given the wide variety of other sources of influence on the adoption of an innovation, the prudent organization will also give credence to the other sources of influence on adoption, and attempt to make them part of their implementation strategy.

\subsection{Informal Channels}

Rogers (1995) argues that positive evaluations of an innovation from near-peers tend to motivate individuals who hear the evaluation to adopt the innovation. He argues that such peer evaluations are important, because individuals seek information from known colleagues (i.e., through informal channels) in order to reduce uncertainty about the innovation. Rogers' assertion about individuals' need to reduce uncertainty is supported by Lewis and Seibold (1996). Rogers (1995) explains:

All innovations carry some degree of uncertainty for the individual, who is typically unsure of the new idea's results and thus feels a need for social reinforcement of the new idea. The individual wants to know that his or her thinking is on the right track, in comparison with the opinion of peers ( $\mathrm{p}$. 168).

In addition to the assertions of Rogers (1995) and Lewis and Seibold (1996), Weenig (1999) argues that information received through informal channels influences attitudes and behavior toward an innovation, Fulk, Schmitz, and Steinfeld, (1990) argue that individuals' perceptions of a technology are shaped through social interactions with peers. Results of the current support prior research, to the extent that exposure to information through informal channels was found to be correlated with adoption in the current study.

Although exposure to information through informal channels was associated with adoption, descriptive data suggested a general lack of use of informal channels. In addition to the $28 \%$ of respondents to the survey who 
indicated that they received no information about the Outlook conversion through informal channels, another $30 \%$ indicated that they disagreed with the statement "I received a great deal of information about Outlook through informal interactions with co-workers." Based on these results, informal interactions were not an important source of information for this particular innovation in this particular organization. Still, as exposure to information from informal sources was found to be more important than respondents' reports of the amount of information received, analysis of the $28 \%$ of respondents who reported receiving no information through informal channels is warranted.

A likely explanation for respondents who reported no use of informal channels is that they may have selected answers to be more socially desirable. That is, respondents may have indicated a lack of information received through informal channels because they perceived participation in "the grapevine" to be socially undesirable. This argument is supported by Moon (1998), who found that individuals completing computer-based surveys (like the one used in the present study) were indeed more likely to provide socially desirable responses than individuals who were responding to the survey orally. This pattern of behavior was reported, despite assurances of anonymity. Moon argues that this behavior may result from a belief that responses are in fact being tracked by the computer, and may ultimately be tied back to the respondent.

Despite the reported lack of utilization of informal channels of information, exposure to information received through informal channels was statistically significantly correlated with adoption. However, perceived credibility of informal sources of information and reported valence of information received through informal sources were not associated with adoption of Outlook. That is, although exposure was associated with adoption, there was no pattern in perceived credibility and reported valence; instead, exposure itself is the foundation of the relationship. These results contradict the findings of scholars who argue that adoption of an innovation is heavily influenced by individuals' perceptions of the attitudes of other members of their social network (Fulk, et al., 1990; Rogers, 1995; Weenig, 1999).

This surprising result may be explained by Kimberly (1981) who argues that attitudes are less important in case of technological diffusion than in other innovation diffusion efforts. Indeed, Weenig (1999) and Lewis and Seibold (1993) studies are of policy and program innovations, which are likely to have been received by potential users very differently than a new technology that required few operating or philosophical changes. The current study provides support for Kimberly's argument. 
However, the results of the current investigation may also indicate that attitudes toward the innovation may not be predictive of actual adoption behaviors in the case of a technological innovation. That is, valence of information received through informal channels may shape attitudes, but adoption behaviors may be influenced by other sources that outweigh the attitudes toward the innovation. Fulk (1993) notes that behavioral compliance does not necessitate an internalization of attitudes. This means that pressure to conform and comply may influence an individual to adopt even in the absence of favorable attitudes toward the innovation.

\section{DISCUSSION OF OBSERVATIONAL DATA}

One the opportunities inherent in the current investigation was the ability to gain insight into the social system that was the context for the diffusion under study. Insights gained through these observations of the social system and implementation process help explain some of the findings discussed earlier. Observations of the social network illuminate the results of the study by highlighting the role of social networks, including accuracy and valence of information received through informal channels. The researcher's own social network demonstrated that even though survey respondents reported receiving little significant information through informal channels, informal channels of information were nonetheless active. In many instances, the information distributed through the grapevine was inaccurate (e.g., "Oh yeah, that's part of PeopleSoft." or "So now, anybody can schedule a meeting on my calendar.").

Although there was no significant relationship between perceived credibility of information and adoption, accuracy of information (a component of credibility according to McCroskey, 1966) is an important consideration in organizational diffusion efforts. The absence of accurate information and the presence of inaccurate information may undermine efforts to diffuse an innovation, and may fuel negative attitudes toward an innovation that must be overcome. In the current study, inaccuracy of information appearing in informal channels of communication was the impetus for determining content in some formal channels. That is, inaccuracy of information regarding the diffusion of groupware in informal channels prompted the need to disseminate accurate information through formal channels. The Groupware Implementation Coordinator was often required to provide accurate information about Outlook and the implementation process to counter inaccurate information presented by organization members at the initial informational meetings held in the individual departments. In fact, part of the rationale for having such 
informational meetings was to correct inaccurate information in an effort to reduce the build-up of negative attitudes toward the innovation. Results of the current study support providing information through such structured implementation activities as the initial informational meetings.

The valence of information also was exhibited through social networks. When the University was considering implementing the newest version of GroupWise across the campus, users of the older version referred to it as "GroupWorse," clearly a comment with negative valence. In addition to the accuracy and valence, communication through social networks proved to be a useful source of horizontal and upward communication in the organization. Information about frequent GroupWise system crashes eventually worked its way up to the Groupware Implementation Team. For example, the researcher heard about frequent GroupWise crashes from colleagues at the University Medical Center and the main campus library, and the researcher shared these observations with the Groupware Implementation Coordinator. Additionally, conversations with systems administrators at other institutions that were using GroupWise revealed similar instability problems. Such information spread through intraorganizational and interorganizational networks, and ultimately prompted a review of the decision to implement GroupWise and rejection of GroupWise in favor of Outlook.

\section{LIMITATIONS OF THE STUDY}

During survey construction, the multiple (and sometimes competing) needs and goals of the researcher and ACS staff led to numerous compromises regarding survey length. This obviously affected the number of issues that.could be addressed, and affected the ability to include multiple measures for constructs to improve reliability. Also, in the editing of the survey, compromises were made for the wording of many questions, imbedding inconsistency in item prompts, and this may have affected the validity of some items. Therefore, these potential threats to the reliability and validity of the survey must be viewed as limitations of the study.

The self-report nature of the data used in the study also must be considered. The data must be interpreted with appropriate consideration given to this fact. Although self-reports of technology-in-use may be more useful than speculative measures that ask respondents to gauge likelihood of future use, the potential threat to validity of survey results from inaccurate self-estimation or social desirability effects must be considered.

The greatest limitation to the study is that of potential response bias. Although the survey yielded a valid data set of 502 responses, the invitation to participate was sent to approximately 1500 potential users. The 
invitational e-mail specifically requested the participation of people who did not or did not plan to use Outlook in an attempt to minimize the likelihood of a sample biased in favor of Outlook users. However, individuals who were not using Outlook at all may not have received the invitation and therefore would have been systematically excluded from the sample. In addition, some Outlook users who did receive the invitation chose not to respond. They may have made this decision for a range of reasons from distrust of electronic surveys to time constraints. This raises serious concerns about the ability to generalize from the data obtained in this study, which the descriptive data suggest are the attitudes and behaviors of adopters of Outlook. The potential exclusion of data from non-adopters and nonrespondents inhibits the ability to draw meaningful conclusions about the influences on adoption for all members of the organization, not just adopters. The potential threat to validity of the results posed by over-representation of Outlook adopters in the survey sample must be considered when interpreting the results.

In addition to the threats to validity posed by data collection and statistical procedures, the absence of some key constructs from the data set must also be viewed as a limitation of the current investigation. Specifically, measures of respondents' attitudes about Outlook would help determine whether or not information received through informal channels was shaping attitudes, and might provide insight into the link between attitudes and adoption behaviors. In addition, a programming error resulted in the omission from the data set of one measure of source credibility of official channels of communication. Finally, an assessment of the perceived importance of the diffusion of Outlook would have been useful in interpreting end-users' perception of the context of the study. For example, the lack of perceived autonomy in adoption of Outlook may seem less significant if the end-users viewed adopting a new software package as something other than an innovation.

\section{IMPLICATIONS FOR FUTURE RESEARCH}

Future research in the intraorganizational diffusion of technological innovations should continue to test the relationship between the influences of near-peers and social networks and end-users' adoption of innovations. Also, the influence of structured implementation activities on adoption should continue to be tested. Although perceptions of information and attitudes were not related to adoption in the current study, they may be more influential in circumstances where the technology is less familiar and compatible, or in the case of non-technological innovations. Also, although 
an on-line survey was a valid and convenient way to collect data in this study, future research in technology diffusion should utilize other methods of data collection as well. Use of focus groups, interviews, paper-and-pencil surveys, and unobtrusive measures may improve the validity of the results obtained, particularly in the case of gathering data about non-adopters. Further investigations of the diffusion of technology may be useful in testing Lewis' (2000) assertion that technology simply is no longer a big deal in organizations, so that the diffusion of a new technology is viewed as an ordinary occurrence in the organization's life cycle.

Other conceptualizations of adoption also may be useful in future research. The technology exists to track time spent using technological innovations. This may provide a more useful measure than self-reports of use. Still, even if the actual use were being tracked, there is no guarantee that the innovation is being used as it was intended when it was implemented. Future investigations may help to further identify the factors that influence not just attitudes and beliefs, but operational adoption. It would be useful to develop a more clear understanding of how information, attitudes, and adoption are linked.

As King and Anderson (1995) indicate, a universal theory of diffusion may elude us. Perhaps what is needed is the ability to understand the multiplicity of factors that influence diffusion, and to be able to examine those factors in context.

\section{REFERENCES}

Allen, T. J., \& Hauptman, O. (1990). The substitution of communication technologies for organizational structure in research and development. In J. Fulk \& C. Steinfield (Eds.), Organizations and communication technology (pp. 275-294).

Bunz, U. K. (1998). Diffusion of innovations: a theory of the past with future. Unpublished manuscript.

Comely, P. (1996). The use of the internet as a data collection method [On-line]. Available: http://virtualsurveys.com/papers/email.htm

Contractor, N. S., \& Eisenberg, E. M. (1990). Communication networks and new media in organizations. In J. Fulk and C. Steinfield (Eds.) Organizations and communication technology, (pp. 143-171). Newbury Park, CA: Sage.

Dawson, P., Drinkwater, R., Gunson, N., \& Atkins, M. (2000). Computer-mediated communication and the virtual workplace: the social and political processes of change. Labour \& Industry, 10(3), 17-38.

Feldman, M.S. (1987). Electronic mail and weak ties in organizations. Office: Technology and People, 3(2), 83-101.

Fulk, J. (1993). Social construction of communication technology. Academy of Management Journal, 36, 921-950.

Fulk, J. \& Desanctis, G. (1995). Electronic communication and changing organizational forms. Organization Science, 6(4), 337-349. 
Fulk, J., Schmitz, J. \& Steinfield, C. (1990). A social influence model of technology use. In J. Fulk \& C. Steinfield (Eds.), Organizations and communication technology (pp. 117-139). Newbury Park, CA: Sage.

Iacono, S., \& Kling, R. (1986). Computerization, office routines, and changes in clerical work. In R. Kling (Eds.) Computerization and controversy: Value conflicts and social choices (309-315). San Diego: Academic Press.

Kimberly, J. R. (1981). Managerial innovation. In P. Nystrom \& H. Starbuck (Eds.), Handbook of organizational design (84-104). New York: Oxford University Press.

King, N., \& Anderson, N. (1995). Innovation and change in organizations. New York, NY: Routledge.

Lewis, B. (2000). IS Survival Guide: End users' resistance to technology and change is based on experience, not instinct. InfoWorld, 22(13), 90.

Lewis, L. K., \& Seibold, D. R. (1993). Innovation modification during intraorganizational adoption. Academy of Management Review, 18(20), 322-354.

Lewis, L. K., \& Seibold, D. R. (1996). Communication during intraorganizational innovation adoption: Predicting users' behavioral coping responses to innovations. Communication Monographs, 63(2), 131-157.

Mahajan, V., \& Peterson, R. (1985). Models for innovation diffusion. Beverly Hills, CA: Sage.

McCroskey, J. C. (1966). Scales for the measurement of ethos. Speech Monographs, 33, 6572.

Poole, M. S., \& DeSanctis, G. (1992). Microlevel structuration in computer-supported group decision making. Human Communication Research, 19, 5-19.

Poole, M.S., Holmes, M., Watson, \& DeSanctis, G. (1993). Group decision support systems and group communication. Communication Research, 20(2), 176-213.

Rice, R. E. (1994). Network analysis and computer-mediated communication systems. In S. Wasserman and J. Galaskiewicz (Eds.), Advances in social network analysis: Research in the social and behavioral sciences (pp. 167-203). Newbury Park, CA: Sage.

Rogers, E. M. (1995). The diffusion of innovations. New York: The Free Press.

Speicher, S. A. R. (1997). Intraorganizational diffusion of communication technology. Unpublished doctoral dissertation, University of Kansas, Lawrence.

Weenig, M. W. (1999). Communication networks in the diffusion on an innovation in an organization. Journal of Applied Social Psychology, 29 (5), 1072-1092. 